\title{
PEMANFAATAN RPTRA SEBAGAI PUSAT KEGIATAN PENGABDIAN MASYARAKAT
}

\author{
Budi \\ Universitas Bunda Mulia \\ Email: @bundamulia.ac.id
}

\begin{abstract}
The Government of Indonesia is committed to respecting and fulfilling the rights of the child. This is reflected in the government's decision to ratify the Convention on the Rights of the Children through Presidential Decree no. 36 of 1990 which was then followed up by the State Ministry of Women's Empowerment through the Regulation of the Minister of State for Women's Empowerment no. 2 of 2009 concerning the Decent Regency / City Children policy (KLA. In 2015, DKI Jakarta Provincial Government targets to build +60 RPTRA in all areas of DKI Jakarta, and +150 other RPTRA in 2016. In the development of RPTRA, the DKI Government uses tripartite development model by involving private parties and universities. Besides the main function as a center for child friendly activities, RPTRA is also expected to be the center of activity and socializing of the surrounding community. As a companion university in the development of RPTRA Dharma Suci, Bunda Mulia University is obliged to assist and coordinate with RPTRA managers so that RPTRA can function as intended. It is lasts from April 2016December 2016. The methods undertaken in carrying out activities in RPTRA are training, seminars, and counseling. The existence of universities in the utilization of RPTRA turned out to help the utilization of RPTRA maximally, and also increase the benefits of community service activities that are done because the right target and as needed. Therefore, the government of DKI Jakarta is expected to accelerate and increase the existence of RPTRA, and maintain the involvement of universities in filling the community service activities in RPTRA.
\end{abstract}

Keywords: child-friendly integrated public space, RPTRA, Jakarta

\begin{abstract}
ABSTRAK: Pemerintah Indonesia memiliki komitmen untuk menghormati dan memenuhi hak anak. Hal ini tercermin dari keputusan pemerintah untuk meratifikasi Konvensi Hak Anak melalui Keputusan Presiden No. 36 tahun 1990 yang kemudian ditindaklanjuti oleh Kementerian Negara Pemberdayaan Perempuan melalui Peraturan Menteri Negara Pemberdayaan Perempuan No. 2 tahun 2009 tentang kebijakan Kabupaten/Kota Layak Anak (KLA).Tahun 2015 Pemprov DKI Jakarta mentargetkan untuk dapat membangun \pm 60 RPTRA di seluruh wilayah DKI Jakarta, dan +150 RPTRA lainnya di tahun 2016. Dalam pembangunan RPTRA tersebut Pemda DKI menggunakan model pembangunan secara tripartit yaitu dengan melibatkan pihak swasta dan perguruan tinggi dalam pembangunan RPTRA dimaksud. Selain fungsi utama sebagai pusat kegiatan ramah anak, RPTRA juga diharapkan menjadi pusat berkegiatan dan bersosialisasi masyarakat sekitar. Sebagai perguruan tinggi pendamping dalam pembangunan RPTRA Dharma Suci maka Universitas Bunda Mulia berkewajiban untuk mendampingi dan berkoordinasi dengan pengelola RPTRA agar RPTRA dapat berfungsi seperti yang dimaksudkan. Periode pendampingan ini berlangsung dari bulan April 2016-Desember 2016. Metode yang dilakukan dalam melaksanakan kegiatan-kegiatan di RPTRA adalah pelatihan, seminar, dan penyuluhan. Keberadaan perguruan tinggi dalam pemanfaatan RPTRA ternyata dapat membantu pemanfaatan RPTRA secara maksimal, dan juga meningkatkan manfaat kegiatan pengabdian masyarakat yang dilakukan karena tepat sasaran dan sesuai kebutuhan. Untuk itu pemerintah DKI Jakarta diharapkan dapat mempercepat dan memperbanyak keberadaan-keberadaan RPTRA, dan mempertahankan keterlibatan perguruan tinggi dalam mengisi kegiatan-kegiatan pengabdian masyarakat di RPTRA.
\end{abstract}

Kata kunci: ruang publik terpadu ramah-anak, RPTRA, Jakarta

\section{PENDAHULUAN}

Di tahun 2015 Pemprov DKI Jakarta mentargetkan untuk dapat membangun \pm 60 RPTRA di seluruh wilayah DKI Jakarta. Sedangkan di tahun 2016 Pemprov DKI merencanakan untuk dapat membangun \pm 150 RPTRA lainnya diseluruh DKI Jakarta. Dalam pembangunan RPTRA tersebut Pemda DKI menggunakan model pembangunan secara tripartit yaitu dengan 
melibatkan pihak swasta dan perguruan tinggi dalam pembangunan RPTRA dimaksud.

Salah satu RPTRA yang dibangun dengan menggunakan model tripartit ini adalah RPTRA Dharma Suci yang terletak di samping pintu tol Jembatan Tiga, Jalan Jembatan Tiga Raya, Kelurahan Pejagalan, Kecamatan Penjaringan, Jakarta Utara. RPTRA yang direncanakan memiliki luas $\pm 5.000 \mathrm{M}^{2}$, . Dalam pembangunan RPTRA Dharma Suci ini Pemerintah Daerah DKI Jakarta bekerjasama dengan Yayasan Dharma Suci sebagai pihak swasta yang bertanggungjawab dalam pembangunan fisik RPTRA, dan Universitas Bunda Mulia sebagai elemen Perguruan Tinggi yang akan mempersiapkan dan melibatkan warga pengguna RPTRA untuk berpartisipasi mulai dari perancangan, pembangunan, dan pengelolaan RPTRA.

a. Tugas utama Universitas Bunda Mulia sebagai universitas pendamping dalam pembangunan RPTRA seperti yang disebutkan di atas dibagi dalam beberapa tahap kegiatan yaitu:

b. Tahap I: Melakukan pemetaan sosial, sosialisasi tentang RPTRA, survey, dan rembuk warga dengan tujuan utama untuk (i) mengidentifikasi kegiatankegiatan yang selama ini dilakukan oleh warga, (ii) menggali informasi dan masukkan dari warga tentang kebutuhan, keinginan dan harapan warga terhadap RPTRA yang akan dibangun. Masukkan dan informasi yang diperoleh digunakan untuk menjadi masukkan terhadap disain RPTRA. Output dari kegiatan tahap I ini adalah disain final RPTRA yang disepakati dan diketahui oleh pemangku kepentingan RPTRA Pejagalan, yang dituangkan dalam berita acara rembuk warga finalisasi disain fisik RPTRA.

c. Tahap II: Melakukan rembuk warga yang bertujuan untuk memfasilitasi pemilihan calon pengelola RPTRA, memfasilitasi kegiatan-kegiatan yang akan dilaksanakan di RPTRA, dan memfasilitasi pembuatan jadwal kegiatan RPTRA. Output dari kegiatan tahap II ini adalah berita acara pengangkatan dan pengesahan pengelola RPTRA.

d. Tahap III: Melakukan pendampingan dan sekaligus berkoordinasi dengan pengelola RPTRA Dharma Suci untuk melakukan kegiatan-kegiatan di RPTRA Dharma Suci sehingga RPTRA dapat berfungsi seperti yang dimaksudkan.

RPTRA Dharma Suci diresmikan oleh Gubernur DKI pada tanggal 06 April 2016. Selanjutnya perguruan tinggi melakukan pendampingan dan sekaligus berkoordinasi dengan pengelola RPTRA Dharma Suci untuk melakukan kegiatankegiatan di RPTRA Dharma Suci sehingga RPTRA dapat berfungsi seperti yang dimaksudkan. Kegiatan pendampingan ini berlangsung sejak peresmian dan penetapan pengelola RPTRA di bulan April 2016 sampai dengan bulan Desember 2016.

\section{TINJAUAN PUSTAKA}

Pemerintah Indonesia memiliki komitmen untuk menghormati dan memenuhi hak anak. Hal ini tercermin dari keputusan pemerintah untuk meratifikasi Konvensi Hak Anak melalui Keputusan Presiden No. 36 tahun 1990. Keputusan Presiden ini kemudian ditindaklanjuti oleh Kementerian Negara Pemberdayaan Perempuan melalui Peraturan Menteri Negara Pemberdayaan Perempuan No. 2 tahun 2009 tentang kebijakan Kabupaten/Kota Layak Anak (KLA).

KLA adalah Kabupaten/Kota yang mempunyai sistem pembangunan berbasis hak anak melalui pengintegrasian komitmen dan sumber daya pemerintah, masyarakat dan dunia usaha, yang terencana secara menyeluruh dan berkelanjutan dalam kebijakan, program dan kegiatan untuk menjamin terpenuhinya hak dan perlindungan anak (Kementerian Pemberdayaan Perempuan dan Perlindungan Anak /KPPA, Tanpa Tahun). Tujuan umum dari KLA adalah untuk memenuhi hak dan melindungi anak. Sedangkan tujuan khusus KLA adalah 
untuk untuk membangun inisiatif pemerintahan kabupaten/kota yang mengarah pada upaya transformasi Konvensi Hak Anak (Convention on the Rights of the Child) dari kerangka hukum kedalam definisi, strategi dan intervensi pembangunan, dalam bentuk: kebijakan, program dan kegiatan pembangunan yang ditujukan untuk pemenuhan hak dan perlindungan anak (PHPA), pada suatu wilayah kabupaten/kota.

Alasan Kementerian Pemberdayaan Perempuan dan Perlindungan Anak dalam mengeluarkan kebijakan Kabupaten/Kota Layak Anak (KLA) antara lain:

1. Jumlah anak sekitar sepertiga dari total penduduk,

2. Anak merupakan bagian yang tidak terpisahkan dari keberlangsungan hidup manusia dan keberlangsungan hidup bernegara,

3. Untuk meningkatkan kualitas anak agar tidak menjadi beban pembangunan

4. Tingginya kekerasan terhadap anak baik dilingkungan sekolah, lingkungan masyrarakat dan lingkungan keluarga,

5. Koordinasi dan kemitraan antar pemangku kepentingan terkait

pemenuhan hak dan perlindungan anak masih lemah dan harus diperkuat agar terintegrasi, holistik dan berkelanjutan,

6. Masih terbatasnya ruang bermain anak yang dapat meningkatkan kreatifitas anak.

Bagi Pemerintah DKI Jakarta, komitmen untuk menjadikan Jakarta sebagai Kota Layak Anak diimplementasi melalui pembangunan Ruang Publik Terpadu Ramah Anak (RPTRA). RPTRA adalah wujud komitmen Pemerintah Provinsi Daerah Khusus Ibukota Jakarta untuk menjamin terpenuhinya hak anak agar anak dapat hidup, tumbuh, berkembang dan berpartisipasi secara optimal sesuai dengan harkat dan martabat kemanusiaan serta mendapat perlindungan dari kekerasan dan diskriminasi (Keputusan Gubernur DKI Jakarta No. 196 tahun 2015;
Keputusan Gubernur DKI Jakarta No. 349 tahun 2015).

RPTRA adalah tempat dan/atau ruang terbuka yang memadukan kegiatan dan aktivitas warga dengan mengimplementasikan $10 \quad$ (sepuluh) Program Pokok Pemberdayaan dan Kesejahteraan Keluarga yang terintegrasi dengan program Kota Layak Anak (Peraturan Gubernur DKI Jakarta No. 196 Tahun 2015). Dalam pergub tersebut dijelaskan bahwa RPTRA dibangun untuk maksud:

1. Menyediakan ruang terbuka untuk memenuhi hak anak agar anak dapat hidup, tumbuh berkembang dan berpartisipasi secara optimal sesuai dengan harkat dan martabat kemanusiaan,

2. menyediakan prasarana dan sarana kemitraan antara Pemerintah Daerah dan masyarakat dalam memenuhi hak anak,

3. Menyediakan prasarana dan sarana kota sebagai Kota Layak Anak,

4. Menyediakan prasarana dan sarana untuk pelaksanaan kegiatan 10 (sepuluh) program pokok PKK,

5. Meningkatkan pencapaian ruang terbuka hijau dan tempat penyerapan air tanah, dan

6. Meningkatkan prasarana dan sarana kegiatan sosial warga, termasuk pengembangan dan pengetahuan dan keterampilan kader PKK.

Selain itu, keberadaan RPTRA juga diharapkan dapat berfungsi untuk menambah ruang terbuka hijau di Jakarta, dan juga sebagai ruang terbuka umum sebagai pusat kegiatan, komunikasi, dan sosialisasi masyarakat sekitar RPTRA. Keberadaan ruang terbuka umum yang memfasilitasi warga untuk berekspresi, berkomunikasi, berbudaya, berorganisasi, kemasyarakatan, dan berkomitmen mutlak diperlukan untuk meningkatkan solidaritas, dan kepedulian warga (Widyawati, Ernawati, \& Dewi, 2011). 


\section{METODE}

Metode yang dilakukan dalam melaksanakan kegiatan-kegiatan pengabdian kepada masyarakat di RPTRA Dharma Suci diantaranya:

a. Pelatihan,

b. Seminar, dan

c. Penyuluhan.

Dalam melakukan langkah-langkah tersebut diatas, Universitas Bunda Mulia menjalin kerjasama dan berkoordinasi dengan Badan Pemberdayaan Masyarakat dan Perempuan dan Keluarga Berencana (BPMPKB) DKI Jakarta, Pihak Kelurahan, Pengurus RW dan RT, serta Tim Penggerak PKK Kelurahan Pejagalan.

\section{HASIL DAN PEMBAHASAN}

Setelah ditandatanganinya Perjanjian Kerjasama antara Pemerintah Daerah DKI Jakarta dan Universitas Bunda Mulia tentang Pemetaan Sosial Kebutuhan
Masyarakat Di Ruang Publik Terpadu Ramah Anak Di Wilayah Provinsi DKI Jakarta pada bulan Agustus 2015, maka Tim Pendamping Pembangunan RPTRA Dharma Suci, Universitas Bunda Mulia mulai melakukan tugas dan fungsinya.

Dengan melewati berrbagai macam tantangan yang ada, akhirnya RPTRA Dharma Suci dapat diresmikan oleh Gubernur DKI pada tanggal 06 April 2016. Selanjutnya Universitas Bunda Mulia bertugas melakukan pendampingan berkoordinasi dengan pengelola RPTRA Dharma Suci untuk melakukan kegiatankegiatan di RPTRA Dharma Suci. Kegiatan pendampingan ini berlangsung sejak peresmian dan penetapan pengelola RPTRA di bulan April 2016 sampai dengan bulan Desember 2016. Adapun rencana dan pelaksanaan kegiatan Pengabdian Kepada Masyarakat Universitas Bunda Mulia selama periode April 2016 - Desember 2016 disajikan pada Tabel 1 dan 2.

Tabel 1. Rencana Kegiatan Pengabdian Kepada Masyarakat

\begin{tabular}{|c|c|c|}
\hline No & Hari/Tanggal & Kegiatan \\
\hline 1 & 15 Mei 2016 & Pelatihan Ibu Hebat Anak Hebat \\
\hline 2 & 23 Juni 2016 & $\begin{array}{l}\text { Pelatihan Membuat Surat Lamaran Kerja dan CV dalam } \\
\text { Bahasa Inggris untuk Siswa Siswi Kelas } 3 \text { SMA/SMK }\end{array}$ \\
\hline 3 & 24 Juni 2016 & $\begin{array}{l}\text { Pelatihan Penelusuran Minat Kerja dan Tips Menghadapi } \\
\text { Interview Kerja Bagi Siswa/Siswi Kelas } 3 \text { SMA/SMK }\end{array}$ \\
\hline 4 & 27 Juli 2016 & $\begin{array}{l}\text { Pelatihan Pengelolaan Keuangan Keluarga bagi Ibu-Ibu } \\
\text { Rumah Tangga }\end{array}$ \\
\hline 5 & 27 Juli 2016 & $\begin{array}{l}\text { Pelatihan Komunikasi Keluarga (Problematika Seksual Pada } \\
\text { Anak) }\end{array}$ \\
\hline 6 & 06 Agustus 2016 & Pelatihan Ayo Belajar Bahasa Mandarin \\
\hline 7 & 06 Agustus 2016 & Pelatihan Ayo Belajar Membuat Simpul Tiongkok \\
\hline 8 & 17 September 2016 & $\begin{array}{l}\text { Teknik Pengelolaan Stress Bagi Ibu Rumah Tangga / } \\
\text { Management Stress }\end{array}$ \\
\hline 9 & 24 September 2016 & Pelatihan Internet Sehat dan Aman bagi Anak-Anak \\
\hline 10 & 24 September 2016 & $\begin{array}{l}\text { Pelatihan Penerapan dan Penggunaan Internet Sehat bagi } \\
\text { Anak }\end{array}$ \\
\hline 11 & 01 Oktober 2016 & Pelatihan Pengelolaan Investasi Bagi Ibu Rumah Tangga \\
\hline 12 & 01 Oktober 2016 & $\begin{array}{l}\text { Pelatihan Pengelolaan Perpustakaan Untuk Membangkitkan } \\
\text { Minat Baca }\end{array}$ \\
\hline 13 & 08 Oktober 2016 & $\begin{array}{l}\text { Pelatihan Penggunaan Materi/Bahan Ajar Otentik Dalam } \\
\text { Pembelajaran Bahasa Inggris untuk Anak-Anak }\end{array}$ \\
\hline 14 & 22 Oktober 2016 & Pelatihan Ayo Belajar Bahasa Mandarin (Sessi 2) \\
\hline
\end{tabular}

Jurnal Pengabdian \& Kewirausahaan Vol. 1 No. 1 


\begin{tabular}{ccl}
\hline 15 & 22 Oktober 2016 & Pelatihan Ayo Belajar Membuat Simpul Tiongkok (sessi 2) \\
\hline 16 & 12 November 2016 & Pelatihan "Bersama Akuntansi, Kita Perduli” \\
\hline 17 & 19 November 2016 & $\begin{array}{l}\text { Pelatihan Menggambar dengan Mengekplorasi Imaginasi } \\
\text { Anak }\end{array}$ \\
\hline 18 & 16 Desember 2016 & $\begin{array}{l}\text { Pelatihan Menggunakan Microsoft Office Untuk Pengelola } \\
\text { RPTRA DHARMA SUCI }\end{array}$ \\
\hline \multicolumn{4}{c}{ Sumber: Data Primer }
\end{tabular}

Dengan dukungan seluruh Sivitas Akademi Universitas Bunda Mulia maka rencana-rencana kegiatan ini pada akhirnya dapat dilakukan dengan baik. Masingmasing program studi melakukan koordinasi dan kerjasama dengan Pengelola RPTRA, Pihak Kelurahan, Pengurus RW dan RT, serta Tim Penggerak PKK
Kelurahan Pejagalan untuk mencari tahu kegiatan-kegiatan yang dibutuhkan dan disesuaikan dengan kemampuan dan keahlian dari Program Studi itu sendiri.

Tabel 2. Pelaksanaan Kegiatan Pengabdian Kepada Masyarakat

\begin{tabular}{|c|c|c|}
\hline No & Tgl & Kegiatan \\
\hline 1 & 15 Mei 2016 & Pelatihan Ibu Hebat Anak Hebat \\
\hline 2 & 23 Juni 2016 & $\begin{array}{l}\text { Pelatihan Membuat Surat Lamaran Kerja dan CV dalam Bahasa Inggris untuk } \\
\text { Siswa Siswi Kelas } 3 \text { SMA/SMK }\end{array}$ \\
\hline 3 & 24 Juni 2016 & $\begin{array}{l}\text { Pelatihan Penelusuran MInat Kerja dan Tips Menghadapi Interview Kerja Bagi } \\
\text { Siswa/Siswi Kelas } 3 \text { SMA/SMK. }\end{array}$ \\
\hline
\end{tabular}




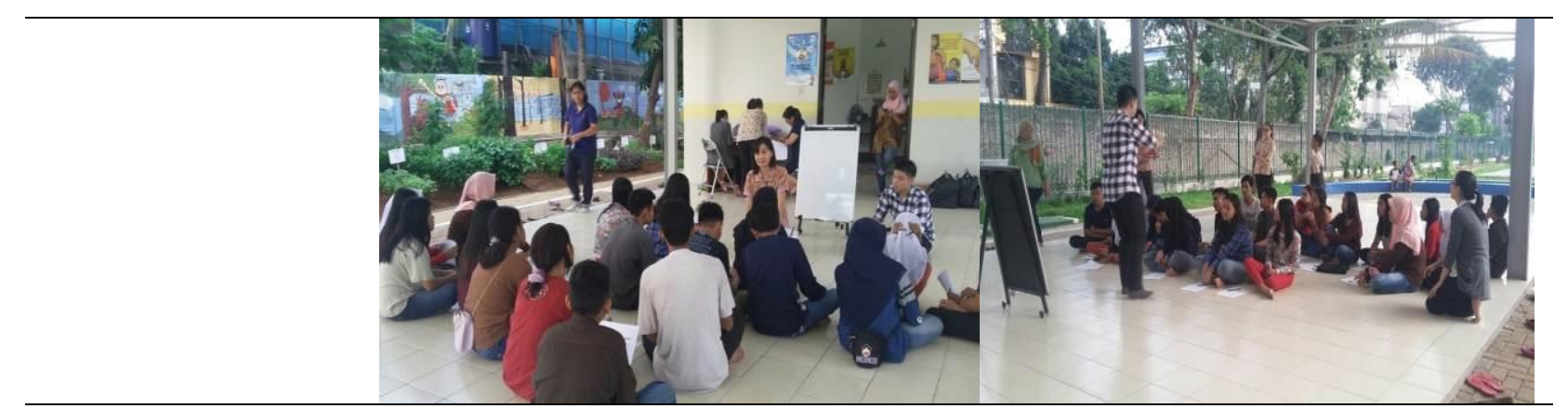

$4 \quad 27$ Juli $2016 \quad$ Pelatihan Pengelolaan Keuangan Keluarga bagi Ibu-Ibu Rumah Tangga.

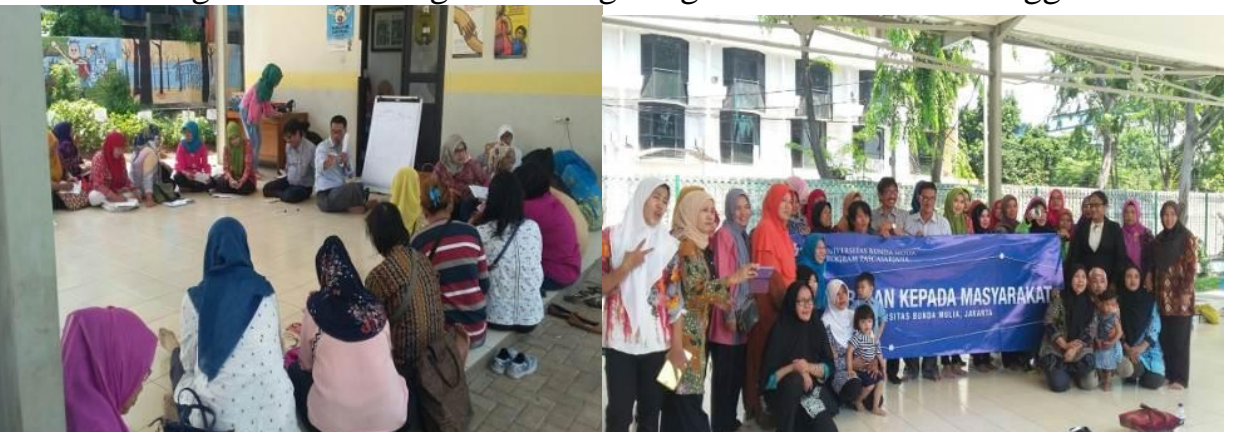

$5 \quad 27$ Juli 2016 Pelatihan Komunikasi Keluarga (Problematika Seksual Pada Anak).

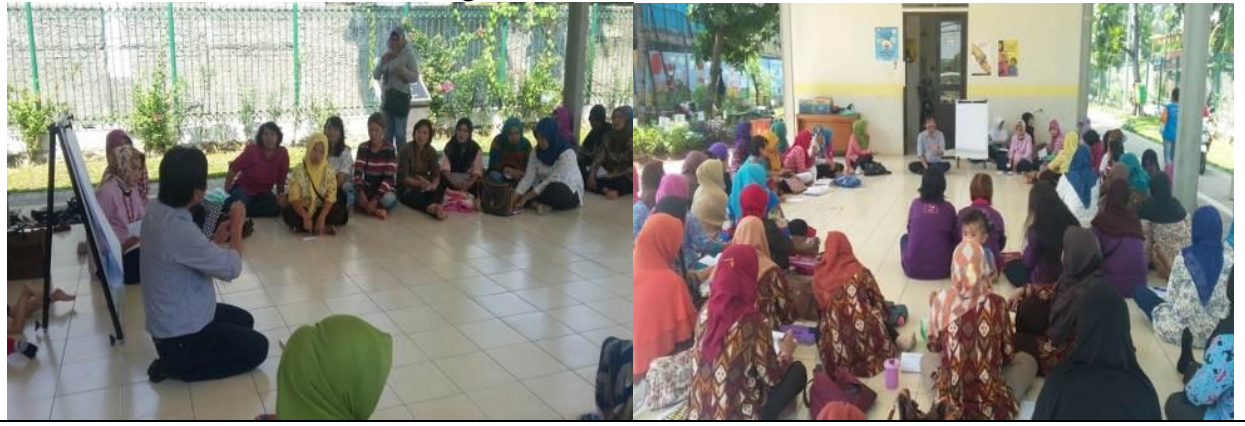

$6 \quad 6$ Agust $2016 \quad$ Pelatihan Ayo Belajar Bahasa Mandarin

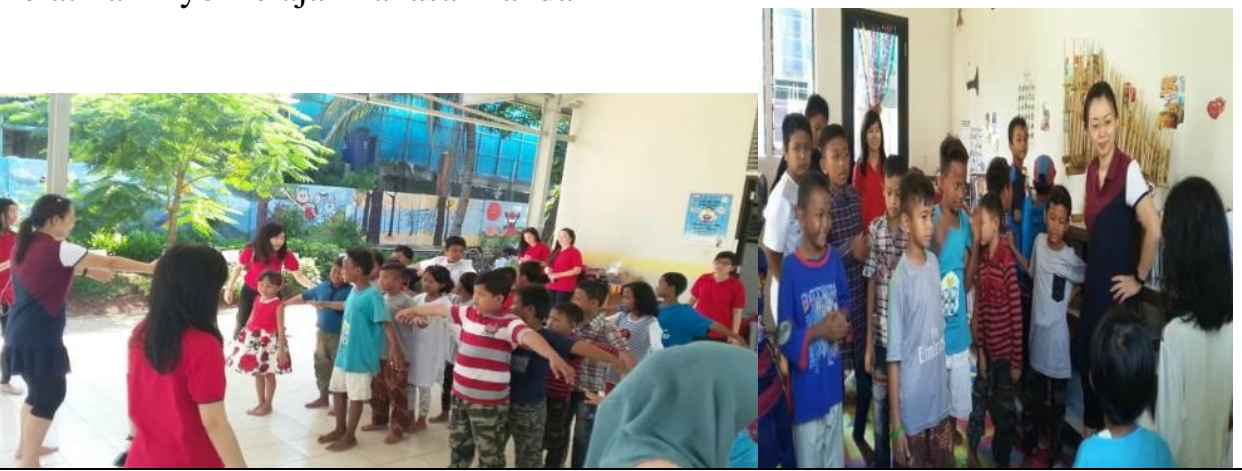

\begin{tabular}{lll}
\hline 7 & 6 Agust 2016 & Pelatihan Ayo Belajar Membuat Simpul Tiongkok
\end{tabular} 

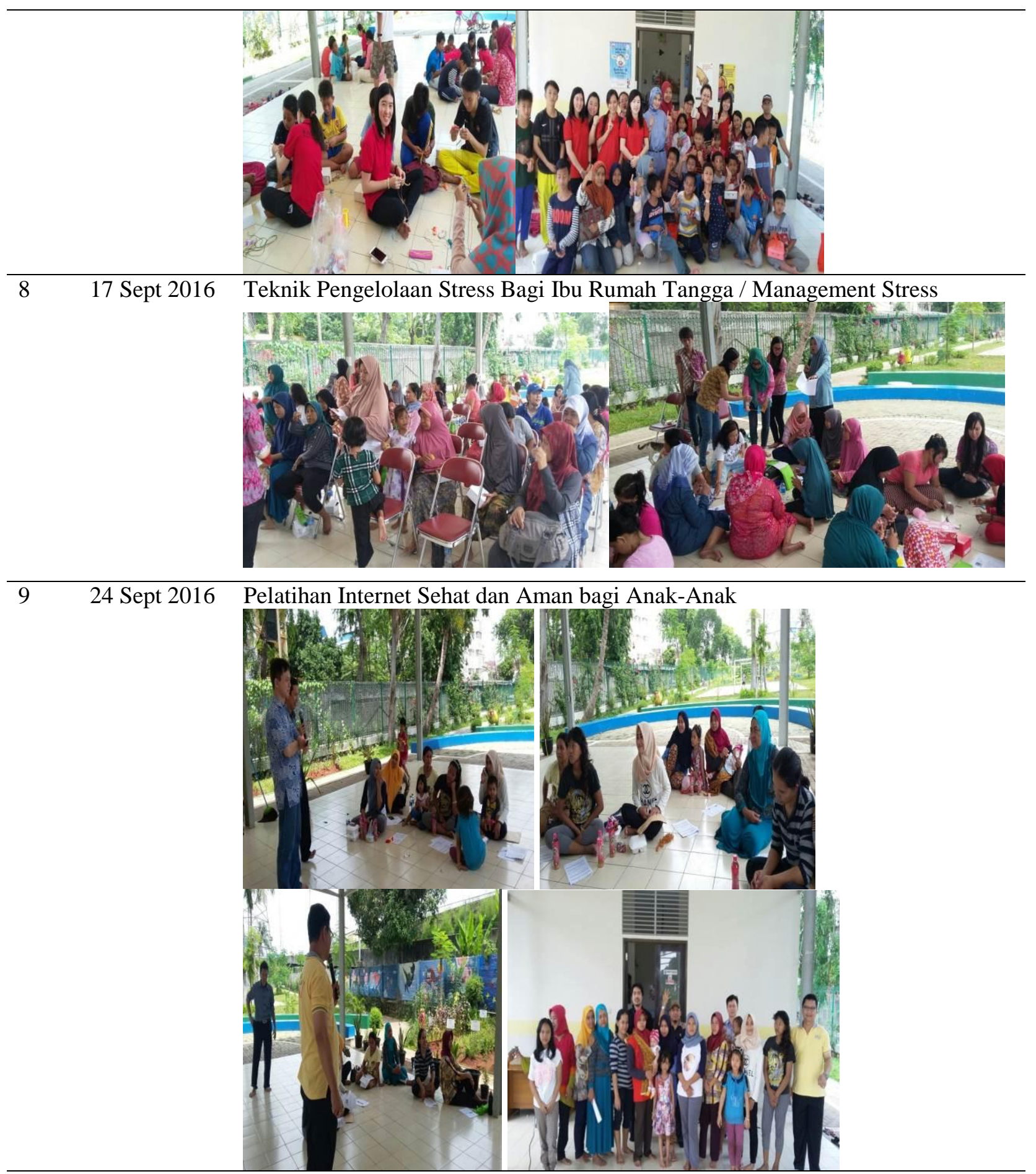

$10 \quad 24$ Sept 2016 Pelatihan Penerapan dan Penggunaan Internet Sehat bagi Anak. 

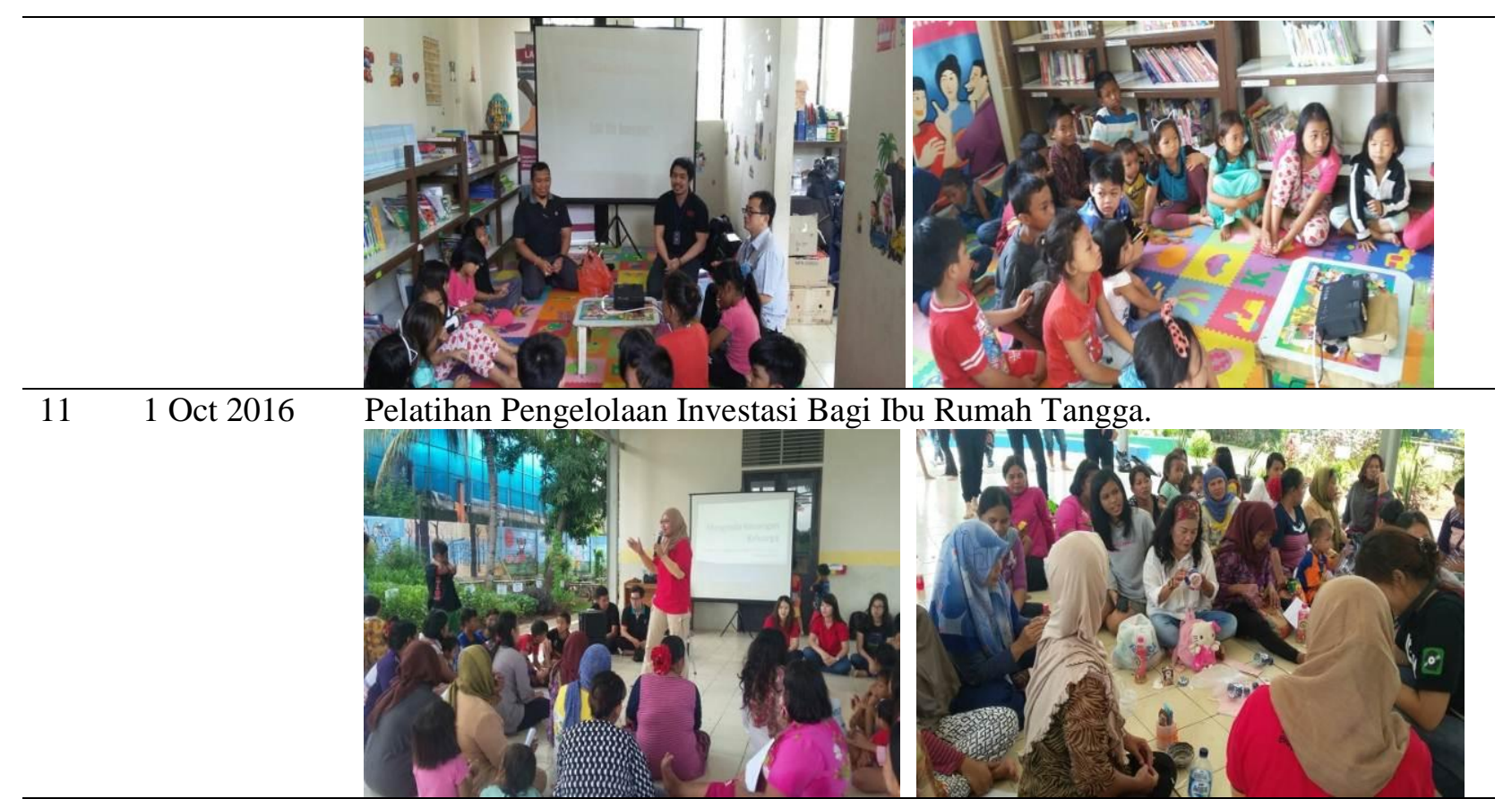

121 Oct $2016 \quad$ Pelatihan Pengelolaan Perpustakaan Untuk Membangkitkan Minat Baca

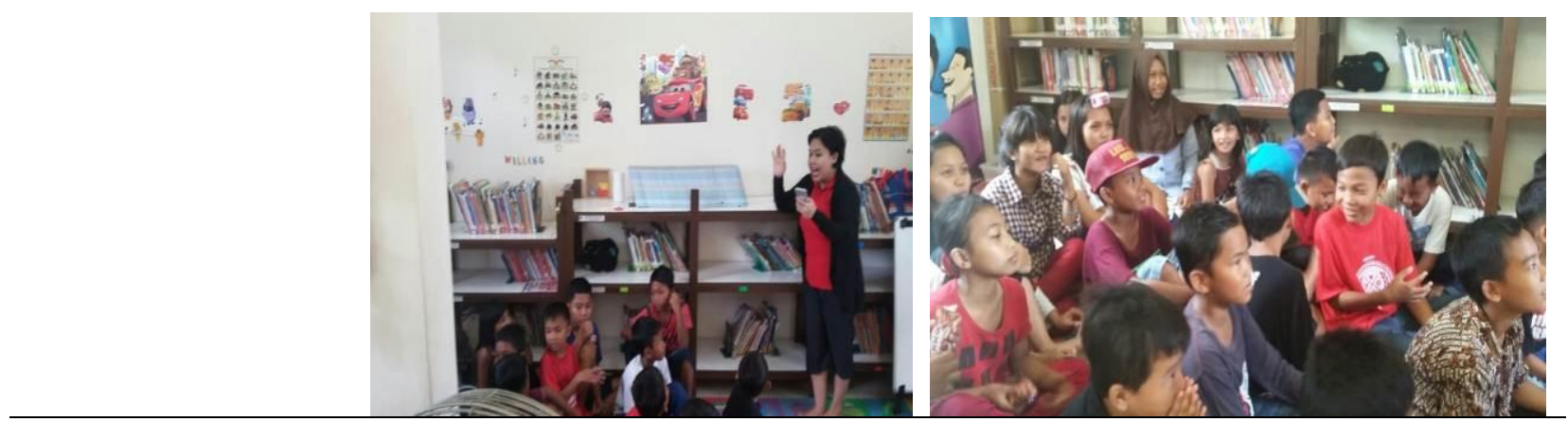

138 Oct 2016 Pelatihan Penggunaan Materi/Bahan Ajar Otentik Dalam Pembelajaran Bahasa Inggris untuk Anak-Anak
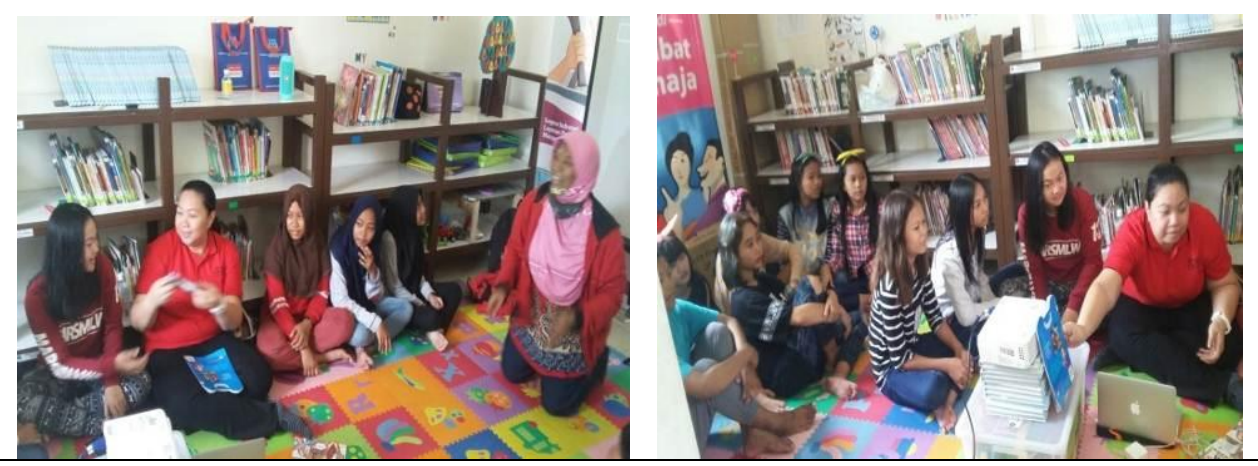

1422 Oct $2016 \quad$ Pelatihan Ayo Belajar Bahasa Mandarin (Sessi 2) 


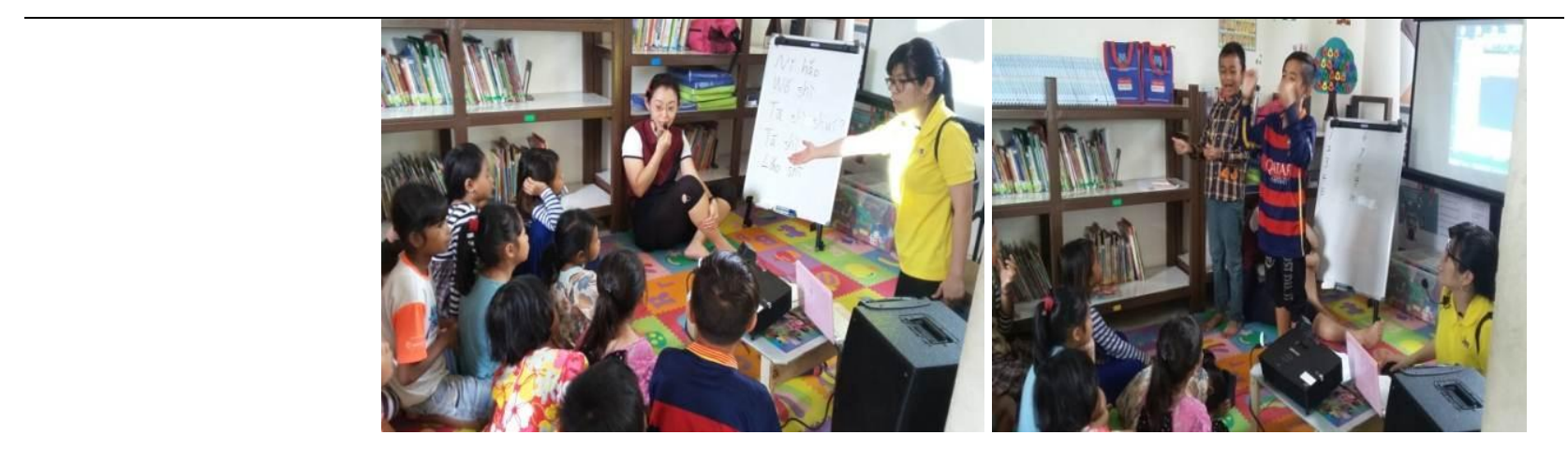

1522 Oct 2016 Pelatihan Ayo Belajar Membuat Simpul Tiongkok (sessi 2)
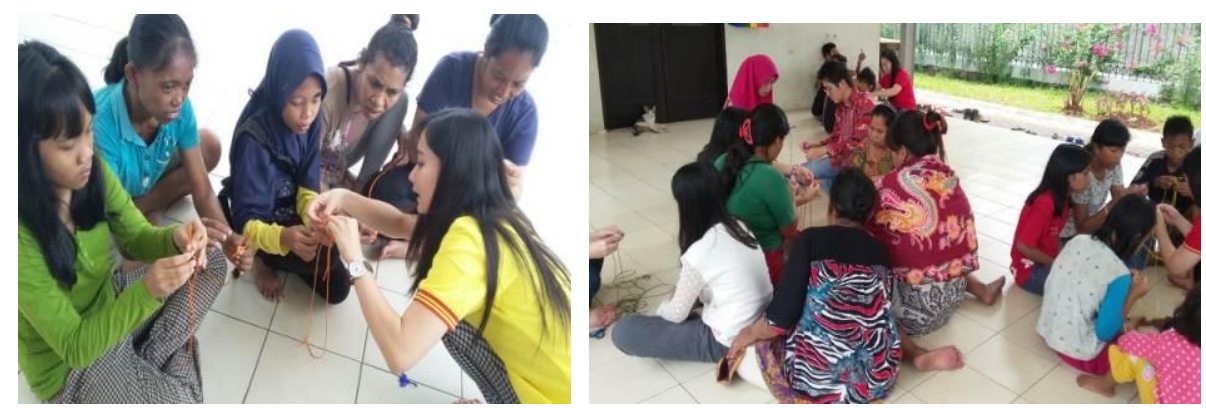

1612 Nov 2016 Pelatihan "Bersama Akuntansi, Kita Perduli"

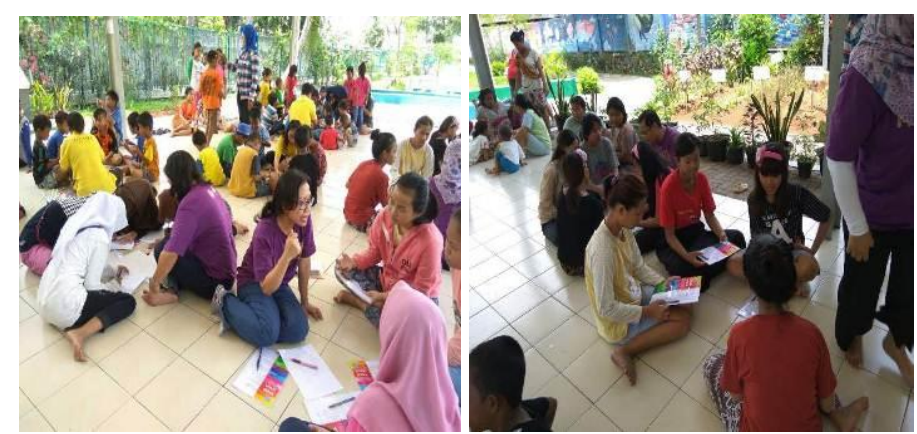

$17 \quad 19$ Nov $2016 \quad$ Pelatihan Menggambar dengan Mengekplorasi Imaginasi Anak

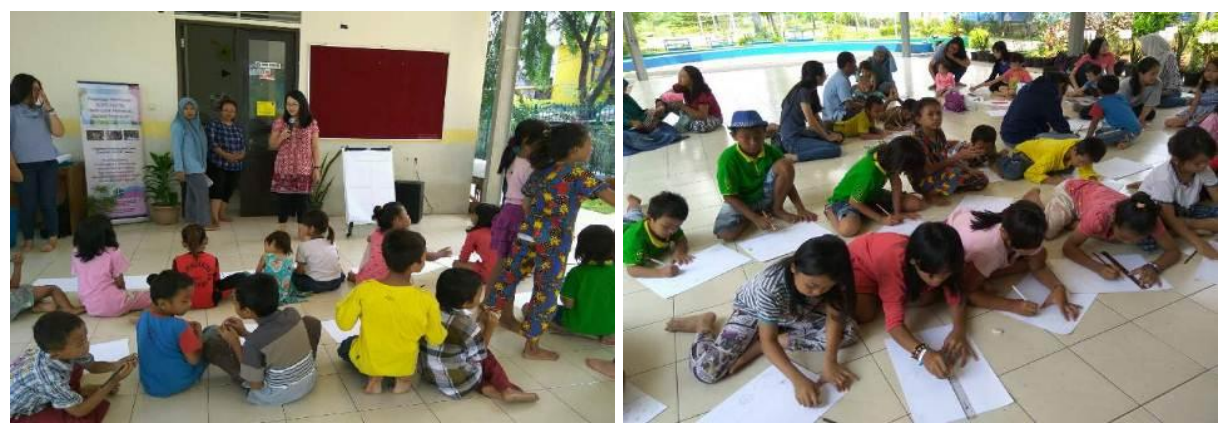

16 Des 2016 Pelatihan Menggunakan Microsoft Office Untuk Pengelola RPTRA DHARMA SUCI

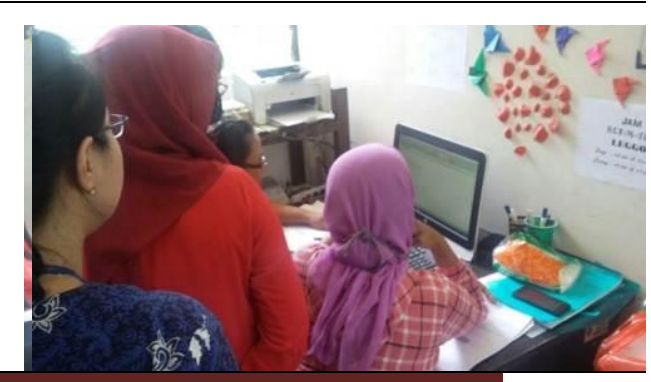

Jurnal Pengabdian \& Kewirausahaan Vol. 1 No. 1 


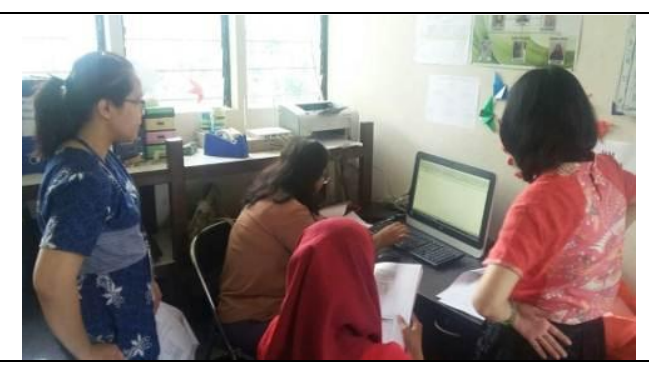

Sumber: Data Primer

\section{SIMPULAN DAN SARAN}

SIMPULAN

Keterlibatan pihak perguruan tinggi untuk menjadikan RPTRA sebagai basis kegiatan Pengabdian Kepada Masyarakat memberikan beberapa manfaat:

1. Dengan melakukan kegiatan pengabdian masyarakat di RPTRA, secara tidak langsung perguruan tinggi membantu RPTRA memenuhi fungsinya sebagai pusat kegiatan masyarakat sekitar RPTRA untuk bersosialisasi, berkomunikasi, dan berkegiatan. Keberadaan ruang terbuka umum yang memfasilitasi warga untuk berekspresi, berkomunikasi, berorganisasi, dan bermasyarakat membantu meningkatkan solidaritas, dan kepedulian warga,

2. Hubungan baik yang tercipta antara perguruan tinggi, pengelola RPTRA, Tim Penggerak PKK Kelurahan, dan masyarakat membantu perguruan tinggi untuk dapat mengidentifikasi kebutuhan masyarakat secara lebih baik. Dengan demikian kegiatan-kegiatan pengabdian masyarakat yang dilakukan perguruan tinggi dapat lebih bermanfaat dan tepat sasaran,

3. Pihak Kelurahan dan Pengelola RPTRA memiliki partner kerjasama untuk memberikan pelatihan-pelatihan dan pemberdayaan yang dibutuhkan oleh masyarakat. Pihak Kelurahan dan Pengelola RPTRA dapat mengidentifikasi kebutuhan-kebutuhan pelatihan yang dibutuhkan oleh masyarakat dan kemudian berkoordinasi dengan pihak perguruan tinggi untuk merancang suatu pelatihan yang memang berdasarkan kebutuhan nyata di masyarakat.

\section{SARAN}

1. Pemerintah DKI Jakarta dapat mempercepat dan memperbanyak keberadaan-keberadaan RPTRA di tengah-tengah masyarakat DKI. Hal ini karena terbukti bahwa RPTRA dapat menjadi salah satu solusi untuk memberikan ruang terbuka umum yang bermanfaat bagi masyarakat,

2. Keterlibatan perguruan tinggi dalam mengisi kegiatan-kegiatan pengabdian masyarakat di RPTRA agar terus dipertahankan dan ditingkatkan. Kehadiran perguruan tinggi dalam pemanfaatan RPTRA menjadikan RPTRA berfungsi sebagai pusat kegiatan dan pemberdayaan masyarakat.

\section{DAFTAR PUSTAKA}

Kementerian Pemberdayaan Perempuan dan Perlindungan Anak, (Tanpa Tahun). Bahan Advokasi Kebijakan KLA, Jakarta

Keputusan Presiden Republik Indonesia No. 36 Tahun 1990.

Patilima, Hamid. (Tanpa Tahun). Kota Layak Anak. Jakarta: Yayasan Kesejahteraan Indonesia

Peraturan Gubernur DKI Jakarta No. 196 Tahun 2015.

Peraturan Gubernur DKI Jakarta No. 349 Tahun 2015.

Peraturan Menteri Negara Pemberdayaan Perempuan No. 2 Tahun 2009

Widyawati, K., Ernawati, A., \& Dewi, F. (2011). Peranan Ruang Terbuka Publik Terhadap Tingkat Solidaritas dan Kepedulian Penghuni Kawasan Perumahan di Jakarta Jurnal Ilmiah Faktor Exacta, Vol.4 No. 3 September 2011, 246-26 